\title{
EDITORIAL \\ 6 Broca's Area and the promulgation of opinion pieces in the JNSPG journals
}

\author{
James T. Rutka, MD, PhD \\ Editor-in-Chief, Journal of Neurosurgery Publishing Group, Charlottesville, Virginia
}

$\mathrm{T}$

HE classic perisylvian paradigm of language function includes a left hemisphere-dominant frontal region known as "Broca's area" and a left superior temporal gyrus segment known as "Wernicke's area" connected by the superior longitudinal fasciculus or arcuate fasciculus. Pierre Paul Broca (1824-1880) was a French physician and surgeon who studied the brains of patients afflicted with speech and language deficits

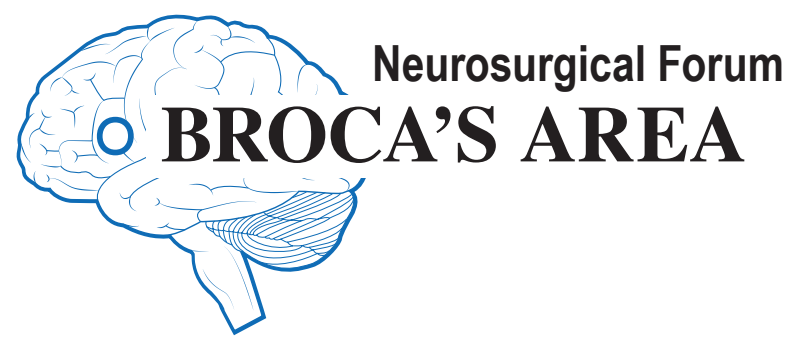

FIG. 1. Broca's Area icon that will now be used to signify opinion pieces published in the JNSPG journals. The icon depicts a sketch, lateral view, of the left cerebral hemisphere with a circle depicting the approximate location of Broca's area (Brodmann's areas 44 and 45). The purpose of articles published in Broca's Area will be to promulgate opinion pieces and to stimulate responses to topical subjects in the field of neurosurgery, and beyond. Artist: Stacey Krumholtz. Figure is available in color online only.
Dr. Albright trained some 20 American neurosurgery residents who came to Kijabe Hospital for 1-month rotations to assist with the burden of neurosurgical disease and incredible caseload that existed in this region. Perhaps more astounding was the clinical research that Dr. Albright and his colleagues conducted on shunt infection rates and complications. Ethical issues in neurosurgery abound in Sub-Saharan Africa, as we learn from Dr. Albright's reflections of the topsy, he demonstrated the critical role of the third convolution of the left inferior frontal lobe in the generation of articulated speech. ${ }^{2}$ His discovery of language localization was among the first to ascribe structure and function to a discrete area of the brain. While the perisylvian paradigm of language function has now ceded to the "dual stream" paradigm consisting of dorsal and ventral streams of white matter tracts, ${ }^{3-5,7}$ still the eponymous areas named after Broca and Wernicke persist and are used to this day. In the case of Broca's area, this term is still quite widely referred to as the region of the brain required for the production of accurate, comprehensible, and meaningful language.

In this issue of the Journal of Neurosurgery: Pediatrics, Leland Albright reflects upon his experience at the Kijabe Hospital in Kijabe, Kenya, where he spent 5 years working as a pediatric neurosurgeon in the underresourced environment of this Sub-Saharan African country. ${ }^{1}$ To state that his work in Kijabe was inspirational and highly motivational is an understatement. Over the years, numbers of children with hydranencephaly who appeared at the hospital for treatment, of the costs of performing laboratory tests or imaging studies in a resource-poor environment, and of the decisions regarding the treatment of children with challenging brain tumors such as craniopharyngioma or medulloblastoma. While not strictly speaking a "scientific submission," "Reflections on developing pediatric neurosurgery in Sub-Saharan Africa" is far too important a paper not to undergo peer review. In addition, Dr. Albright's "reflections" allow us to gain further insights from thought leaders in the field of global surgery. As global surgery has now come of age with the publication of the Lancet Commission's articles on this topic, ${ }^{6}$ so the three editorials written by Drs. Mark Bernstein and George Ibrahim, Graham Fieggen, and Ben Warf are timely and highly informative. ${ }^{1}$

With the launch of Broca's Area as a forum for opinion pieces in all four Journal of Neurosurgery Publishing Group (JNSPG) journals, from time to time these pages 
will showcase works to stimulate responses from our readership in the form of commentaries, editorials, letters to the editor, and in social media. These opinion pieces will be readily identifiable within the journals by the Broca's Area icon to the left of the title. The icon depicts a lateral neuroanatomical sketch of the left hemisphere with a circle placed in the approximate location of Broca's area (Fig. 1). I do hope you will enjoy reading this opinion piece by Dr. Albright and seeing future contributions in the JNSPG journals under the moniker of Broca's Area.

http://thejns.org/doi/abs/10.3171/2016.1.PEDS1614

\section{References}

1. Albright AL: Reflections on developing pediatric neurosurgery in Sub-Saharan Africa. J Neurosurg Pediatr [epub ahead of print April 15, 2016. DOI: 10.3171/2015.8. PEDS15403]

2. Berker EA, Berker AH, Smith A: Translation of Broca's 1865 report. Localization of speech in the third left frontal convolution. Arch Neurol 43:1065-1072, 1986

3. Chang EF, Raygor KP, Berger MS: Contemporary model of language organization: an overview for neurosurgeons. J Neurosurg 122:250-261, 2015

4. Dick AS, Tremblay P: Beyond the arcuate fasciculus: consensus and controversy in the connectional anatomy of language. Brain 135:3529-3550, 2012

5. Friederici AD: The brain basis of language processing: from structure to function. Physiol Rev 91:1357-1392, 2011

6. Meara JG, Hagander L, Leather AJ: Surgery and global health: a Lancet Commission. Lancet 383:12-13, 2014

7. Poeppel D, Emmorey K, Hickok G, Pylkkänen L: Towards a new neurobiology of language. J Neurosci 32:14125-14131, 2012 